the tides are determined separately, so as to examine any seasonal variations of the constants. A second paper dealt with wind-bores in the ports of Trieste and Venice; it appears that this wind-bore traverses the gulf of Venice without change of direction, lateral expansion and with little loss of speed.

Prof. H. Berg (Cologne) dealt first with "The Velocity Profile in Rivers" - an attempt to express the vertical velocity gradient of rivers by a logarithmic law using certain ideas of Prandt concerning turbulent flow over rough surfaces. In a second paper, on "Examples of Trivial Correlations in Solar Terrestrial Relationships", Prof. Berg examined two such examples: Farthing's experiment, which led him to conclude that a period of intense coronal radiation is followed by a penetration of cold air over the Earth; and an investigation by Abbott, who claimed that the solar constant is considerably lowered on days of intense geomagnetic storms. Prof. Berg showed that the results in both cases are only the outcome of faulty mathematical reasoning.

Prof. G. Berbesconi (Genoa) considered the "Partial and Total Representation of an Ellipsoid on the Sphere". Starting from the principle of the minimum energy of deformation of an elastic ellipsoidal geographical network, Prof. Berbesconi determines a relationship between the ellipsoid of gyration and the local spherical surface in the neighbourhood of the oscillation point up to a radius of $250 \mathrm{~km}$. He next examines various functions the extremals of which give a good representation of the whole ellipsoid on the sphere and define a new latitude which he considers useful for the construction of geographical globes.

Dr. I. Dagnino (Genoa) considered the "Frequency of Cyclones and the Distribution of Cloud in the Mediterranean", using the synoptic charts for all the days during the period 1946-55. For the case of the region of maximum frequency, Dr. Dagnino has examined and discussed the principal atmospheric and meteorological factors giving rise to these cyclones-in addition to the seasonal factors.

Prof. Bossolasco (Genoa) spoke on some work he has done with collaborators on "The Atmospheric Electric Potential in the Layers close to the Ground". The result of a series of observations (with Drs. Dagnino and Romagnone) to determine the variation of the atmospheric electric field near ground-level showed a decrease of the potential gradient from a height of $1 \mathrm{~m}$. to $2 \mathrm{~m}$., and a further decrease at a height of $3 \mathrm{~m}$. The variation at discrete potentiallevels confirms electrically the presence of a boundary layer near the ground. A second communication dealt with the "Measurement and Continuous Recording of the Salinity of the Atmosphere". The apparatus used for the purpose is one developed by F. Meda, based on the principle of collecting the radioactivity by passing the air through water.

Prof. M. Cutolo (Naples) spoke on "The Measurement and Behaviour of the Geomagnetic Field at the Lower Border of the E-layer'. He described how this can be effected by taking the mean of the frequencies of the two maxima in the gyro-interaction curve and pointed out that the measurements of the geomagnetic field would be very accurate. Prof. Cutolo also spoke on "The Effects of Demodulation in the Ionosphere" ; this method also provides an alternative method of measuring the geomagnetic field in the $E$-layer.

"Micropulsation in the Geomagnetic Horizontal Force and in Telluric Currents" was the subject of a paper by Dr. K. Burkhat (Munich). Dr. Burkhat pointed out that although the close connexion between geomagnetic variations and telluric currents has been known for more than a century, it has only recently been possible to decide which of the two phenomena is the cause and which the effect. At large distances from the electrodes, and in the case of small periods, the respective phases are in good accord. But for small periods (diurnal variation) and close to the electrodes, one finds a definite difference in the phase of the currents with respect to the geomagnetic variations. The difference in phase can be explained as due to the effect of resistance and reactance, since we now know that every telluric current connected with geomagnetic variation is due to induced currents. Dr. Burkhat then considered the statistics of pulsations and noted that the frequency curve for pulsations with periods of about 30 sec. coincides very nearly with the variation of maximum electron density in the $E$ - and $F_{1}$-layers.

Prof. M. Matschinski (Paris) next spoke on "Problems of Geochemistry". He confined himself to what he described as the geographical aspects of geochemistry-which problem he formulated as that of finding the relationship between the chemical and geographical traits of given regions. As an example, he considered volcanic regions in the form of ares; he recalled that he has already found a relationship between the density and the radius of curvature of the arcs. Prof. Matschinski showed several graphs with the view of demonstrating a statistical interdependence between geographical traits and certain chemical characteristics of rocks of the regions considered; for example, the mean percentages of the oxides of silicon, aluminium, calcium, magnesium, sodium, potassium and iron. These results were obtained from more than two thousand analyses.

The prize for meteorology offered by the Society was awarded to Prof. A. Giao and M. Ferreira for their paper "Introduzione alla climatologia dinamica dell'America Settendrionale, del Nord-Atlantico e dell'Europa". The following officers were elected for the period 1956-59 : President, Prof. M. Bossolasco, Council, Profs. Aliverti, Lovera and Ranzi ; Secretary, Dr. I. Dagnino. V. C. A. Ferraro

\section{MEMBRANE PHENOMENA}

\section{FARADAY SOCIETY DISCUSSION}

$\mathrm{T}$ THE Faraday Society held a general discussion on "Membrane Phenomena" in the University of Nottingham during April 10-12. Nearly two hundred scientific workers attended the discussion, the first of its kind to be held in Nottingham. The president, Mr. R. P. Bell, took the chair for the whole of the meeting, and the proceedings were opened by the sending of a message of greeting to Prof. F. G. Donnan, a founder-member and pastpresident of the Society, who is well known for his work in the field of membrane equilibria.

The discussion proper was preceded by the Spiers Memorial Lecture, given on this occasion by Prof. $T$. Teorell (Upsala), whose subject was "Transport Phenomena in Membranes". Prof. Teorell indicated how his own interest sprang originally from biochemical studies on hydrochloric acid in the stomach. $\mathrm{He}$ outlined structural studies on cell membranes, showing slides of striking electron micrographs taken 
by F. S. Sjöstrand. He stated that theories must explain the five phenomena of ionic transport, membrane potential, electrical conductivity, ionic distribution equilibria, and the potential gradient and spatial distribution of ions within the membrane. In this connexion he discussed the achievements of four theories: those of the porous membrane, the homogeneous membrane, the energy-barrier model, and the fixed-charged membrane model. He pointed out how concentration gradients within a membrane may be in the reverse direction to the overall gradient between the two bulk solutions on each side of the membrane, leading to anomalous transport. $\mathrm{He}$ surveyed most ably the whole range of phenomena from the collodion membranes of Michaelis to the recent results of the Cambridge physiology school, concluding with reference to his own recent model which shows rhythmic variations of potential.

The general introduction was given by Prof. G. Scatchard (Massachusetts), who briefly outlined the programme to be followed, emphasizing the key part to be played by the thermodynamics of irreversible processes. 'T. L. Hill's (Bethesda) paper showed how the McMillan-Mayer solution theory, applied to the membrane equilibrium problem, leads directly to a value for the osmotic pressure. A combination of this theory with the classical Donnan method in certain instances leads to the membrane potential. $R$. Schlögl (Göttingen) divided total particle fluxes into those relative to the local centre of gravity, and a convection common to all particles, and showed that the latter may play an important part in membranes with an appreciable water permeability.

M. Nagasawa and I. Kagawa (Nagoya) found that the slope of the straight line connecting membrane potential and the logarithm of the ion activity for an ion-exchange membrane is less than $R T / F$, which they explained by abnormal ion activities within the membrane. F. Bergsma and A. J. Staverman (Delft), discussing a similar discrepancy for bi-ionic potentials, have found it particularly marked for hydrophile membranes and suggested water transport as the cause. G. Scatchard and F. Helfferich (Massachusetis and Göttingen) have found the abnormally high potentials observed in various cells with cation exchange membranes to be most marked when ions of different valence are present and to be markedly reduced by suitable stirring. They attribute the observations to a preference of the membrane surface for divalent ions. F. Helfferich (Göttingen) discussed the effects of Nernst diffusion films adherent to the membrane on its permeability. R. Neihof and K. Sollner (Upsala and Bethesda) have calculated rates of exchange of ions from membrane potentials of bi-ionic systems, demonstrating ionic selectivities approaching those observed in biological systems.

G. Manecke and H. Heller (Berlin-Dahlem) discussed the separation of non-electrolytes from electrolyces using an ion-exchange membrane, a problem also of interest to T. S. Mackie and P. Meares (Aberdeen), who compared sorption isotherms and diffusion-rates of ethanol in 'Zeocarb 315'. The ethanol is salted-in to the membrane, and it appears that two-thirds is in solution in the water swelling the membrane and free to diffuse, the remaindt 1 being adsorbed on the polymer chains.

J. W. Lorimer, E. I. Boterenbrood and J. J. Hermans (Leyden) have investigated membranes of viscose and sodium carboxymethyl cellulose, carrying out six measurements-specific conductivity, two transport numbers, two diffusion coefficients, and permeability -in order to permit evaluation of the six phenomenological coefficients of the thermodynamic theory. A. Despic and G. J. Hills (London), using membranes of cross-linked polymethacrylic acid, have subtracted electrosmotic flow from total flow, thus obtaining the flow due to solvated counterions. The latter quantity leads to a value of $9 \pm 1$ for the solvation number of sodium ion within the membrane. H. P. Gregor and D. M. Wetstone (Brooklyn) dealt with selective transport across sulphonic and carboxylic cationic membranes.

K. S. Spiegler, R. L. Yoest and M. R. J. Wyllie (Pittsburgh) considered the electrical potentials arising kcross porous plugs of ion-exchange materials, separating two solutions of the same electrolyte. In dilute solutions such plugs give almost perfect membrane potentials; but in concentrated solutions, conductance occurs largely through liquid in the pores, and the potential difference approaches the liquid-junction potential. The results are shown to be relevant to the suspension effect observed in $p H$ measurements on suspensions and gels using a combination of glass and calomel electrodes. 'T. R. E. Kressman and F. L. Tye (London) showed how the transport numbers of sodium and chlorine ions in certain ion-exchange membranes decrease with increase in current density, an effect attributable to concentration diffusion. D. Hutchings and R. J. P. Williams (Oxford) considered how far cation-exchange membranes are suitable for analytical use. They have found conditions on the whole to be unfavourable, equilibrium potentials being reached only slowly, and in any case being often lower than those expected on thermodynamic grounds.

The last session was devoted to the properties of biological membranes. D. D. Eley and D. G. Hedge (Nottingham) examined the interaction of protein solutions with lipoid monolayers by a development of the Schulman-Rideal technique. Increases in surface pressure were interpreted to show the formation of a first sublayer of fully uncoiled protein chains, and a secondary layer consisting possibly of nacive protein. A. Rothstein (Rochester, N.Y.) concluded from studies of yeast cells that the cell surface is a "multimembrane compartmentalized structure". There is an outer barrier impermeable to proteins and holding enzymes such as saccharase and phosphatase. Within this there is a second membrane impermeable to anions and bivalent cations but permeable to potassium and hydrogen ions. Finally, there is a barrier impermeable to potassium and hydrogen ions, and containing metabolic pumps for phosphate and potassium ions. Dr. Rothstein outlined the evidence supporting this model : exchange reactions with radioisotopes are playing a big part in this kind of work.

W. D. Stein and J. F. Danielli (London) defined 'facilitated diffusion' as involving a specific structural relationship between the membrane and the diffusing species. As a model for the permeability of red-blood cells to glycerol, they consider a pore, possibly of protein, containing hydrogen-bonding groups that complex with the glycerol and lead to the observed kinetics, which are of the saturation or MichaelisMenten type. Various glycols and alcohols were shown to be competitıve inhibitors for the diffusion, and copper a non-competitive inhibitor. Freda Bowyer and W. F. Widdas (London) discussed the same problem for glucose and red-blood cells, considering in particular the kinetics of inhibition by dinitrofluorobenzene, which appears to be a fourth-order reaction. P. Mitchell 
and J. Moyle (Edinburgh) have found the specificity and kinetics of phosphate transport in Staphylococcus aureus to resemble those for enzyme-linked reactions, and suggested that the enzyme-substrate complex forms the carrier for the facilitated diffusion. In the closing paper, R. D. Keynes and R. H. Adrian (Cambridge) deseribed how in resting nerve or muscle the membrane is 25-100 times more permeable to potassium ion than sodium ion, the inside of the fibre being negative to the outside. As the action potential ariives, the membrane changes so that sodium ion becomes the more permeable ion, the inside of the fibre now becoming positive. There is no model to date which will account for the observation that the ratio of the permeability of sodium ion to that of potassium ion is linked to the electrical polarization of the adjacent membrane.

There was a lively discussion on many of the papers, and a number of contributors sought to show how ion-exchange systems can lead to a selective action on different cations. On the whole, it seemed that there is still something of a gap between the achievements of the physical chemist and the needs of the biologist with his complex systems; but it seems clear that this general discussion, and the published account which will appear in due course, should do much towards the further closing of this gap in the future. It is clear that the Faraday Society continues to provide a unique forum for the development of the border-line sciences.

\section{D. Euey}

\section{ROYAL COMMISSION ON AWARDS TO INVENTORS}

\section{FINAL REFORT}

T HE fourth and final report of the Royal Commission on Awards to Inventors* concludes the record of the Commission's work. Besides listing decisions of the Commission since November 9,1952 , it discusses certain aspects of the more important of the 115 claims considered since the issue of the previous report. Only nine claims were dealt with under Head 1 of the Warrant during the period, and the Commission from the outset indicated its reluctance to deal with patent claims where the validity of the patent was seriously challenged. Several claims have consequently been referred to the Courts and other claimants have elected to have their claims considered under Head 3, that is, under the exercise of the Crown's bounty in granting an ex gratia award. By far the majority of claims heard by the Commission have been brought by such claimants, who have waived, or have not possessed, legal rights to support their claims. This procedure cannot be applied to claimants possessing patent rights who, after the period to which their claim relates, have assigned their patents to a third party. Normally, at the request of the Crown, the Commission has taken into account, in estimating the utility of the invention, its possible future use by the Crown as well as the past use. In a claim by J. R. Geigy S.A. and the Geigy Co., Ltd., relating to dichlorodiphenyltrichloroethane, the patents covering the invention had; at the date of hearing, been transferred to a

* Royal Commission on Awards to Inventors-Fourth and Final newly formed company which was not a party to the claim, and the claimants undertook either to amend the claim by joining the patentees or to obtain an undertaking safeguarding the Crown from any further claim.

From time to time it has been urged on the Commission that exceptionally large use of an invention should be taken not merely as an important factoi but as the predominant factor in determining the quantum of an award. It was on this principle that, in view of evidence showing the highly effective use of rockets in the later stage of the War, both in regard to material and to morale, the Commission, notwithstanding the heavy discount which the status of the claimants involved, recommended an award of $£ 5,000$ for the invention of a loose-charge rocket motor. In regard to novelty and originality of invention, the material question which has weighed with the Commission has been whether it has been the earlier or later publication or communication which has in fact led to the practical use of the invention by the Crown; nor has the fact that the claimant has patented his invention abroad, and thereby knowledge of the invention has been made available to an enemy country, necessarily disqualified the claimant from receiving an ex gratia award. Accordingly, the Swiss firm of J. R. Geigy S.A. was not disqualified from receiving an award in respect of the exceptional usefulness of DDT as a means of safeguarding the health of British troops; in the same way, notwithstanding the fact that the information contained in the late Prof. N. A. V. Piercy's earlier papers dealing with the mathematical basis of the design of aerofoil sections had become common knowledge among aeroplane constructors, the Commission, in view of evidence that his subsequen's confidential communications to the Air Ministry were of permanent value for the constiuction of aerofoils, recommended an award.

The Commission has occasionally, as in connexion with the Pritchard principle for constructing bombsights, recommended an award where the inventive merit of the contribution consisted mainly of mathematical or theoretical calculations. Claims by employees of Crown contractors have generally been treated on the principle that, if the invention was made in fulfilment of the employee's duty to his employers, he should look to the firm he serves for an ex gratia reward for such services. The Commission was, however, able to treat the status of the claimants in the project known as Pluto and the inventors of the cavity magnetron as substantially the same as that of research workers directly paid by the Crown, since at the time they were lent or seconded to a government department for carrying out the experimental work which led to the invention. An award could be recommended to the inventor of the winged target or pilotless aircraft for towing behind aircraft because the company employing the inventor had waived its claim as patentees against the Crown in favour of the inventor. An award of $£ 2,500$ was recommended in respect of the disk seal triode in spite of some dubiety as to the validity of the claim, in view of some ambiguity in the contract in force and of the merit and extensive usefulness of the technique, particularly in blind firing from ships.

The gratuitous offer to the Crown and its contractors of the free user of a patented invention does not necessarily disqualify the owner of the patent from afterwards qualifying for an ex gratia award; but the Commission has held that surgical or medical 